\title{
ANALISIS TIPOLOGI DAN KOMPOSISI PENDUDUK PADA KAMPUNG TUA TANJUNG RIAU, SEKUPANG
}

\author{
${ }^{1}$ I Gusti Ngurah Anom Gunawan, ${ }^{2}$ Carlos Willyam \\ 1-2Universitas Internasional Batam, Batam, Indonesia \\ Yenlong655@gmail.com
}

Informasi Naskah

Diterima: 31/05/2020; Disetujui terbit: 29/12/2020; Diterbitkan: 29/12/2020;

http://journal.uib.ac.id/index.php/jad

\begin{abstract}
ABSTRAK
Kota Batam sangat terkenal dengan wilayah permukiman pesisirnya. Salah satunya yaitu Tanjung Riau. Tanjung Riau adalah nama kelurahan yang berada di kecamatan Sekupang, Kota Batam, Kepulauan Riau, Indonesia. Luas wilayah kelurahan ini adalah 23,90 km², dengan jumlah penduduk tahun 2020 sebanyak 23.987 jiwa dan kepadatan 1.004 jiwa / km². Kampung tua ini merupakan wilayah yang sangat berpotensi sebagai destinasi kunjungan warga luar jika diperbaiki sistemnya dan dikelola dengan baik. Oleh sebab itu, penelitian ini berfokus pada tipologi bangunan dan komposisi penduduk dan akan dicari indikasi masalah yang ditemukan sehingga dapat memberikan solusi sebagai pemecahan masalah pada penelitian tersebut.
\end{abstract}

Kata Kunci: Kampung tua, Tanjung Riau, Tipologi

\section{ABSTRACT}

Batam City is very famous for its coastal settlement areas. One of them is Tanjung Riau. Tanjung Riau is the name of a sub-district located in Sekupang sub-district, Batam City, Riau Islands, Indonesia. The area of this kelurahan is $23.90 \mathrm{~km}^{2}$, with a population in 2020 of 23,987 people and a density of 1,004 people / $\mathrm{km}^{2}$. This old village is an area that is very useful as a visit destination if the systems and facilities are well managed.. Therefore, this research is based on the typology of buildings and population composition and the problems found will be sought so that they can provide solutions to problems in the research.Keywords: basic sanitation, coastal settlement, Penyengat Island

Keywords: Old Village, Tanjung Riau, Typology 


\section{Pendahuluan}

Tanjung Riau adalah nama kelurahan yang berada di kecamatan Sekupang, Kota Batam, Kepulauan Riau, Indonesia. Luas wilayah kelurahan ini adalah 23,90 km², dengan jumlah penduduk tahun 2020 sebanyak 23.987 jiwa dan kepadatan 1.004 jiwa/km². Kampung Tua Tanjung Riau yang bercirikan melayu termasuk salah satu dari 37 Kampung Tua yang ada di Kota Batam yang berlokasi di daerah Sekupang (Batam bagian Barat). Daerah Sekupang juga disebut Sungai Pembunuh, karena pada zaman dahulu banyak perompak yang dihukum mati oleh algojo di daerah ini. Sampai sekarang, daerah Sekupang berdiri tiga pelabuhan kapal yaitu Pelabuhan Rakyat yang menghubungkan pulau Batam dengan pulau-pulau kecil disekitar pulau Batam. Kemudian Pelabuhan Domestik yang menghubungkan pulau Batam dengan Pulau Karimun, Pulau Bintan dan Pulau Sumatera, serta Pelabuhan Internasional yang menghubungkan pulau Batam dengan Singapura.Tujuan penelitian ini akan membahas mengenai rumusan masalah tipologi bangunan dan komposisi penduduk untuk mengembangkan sarana lokasi tersebut.

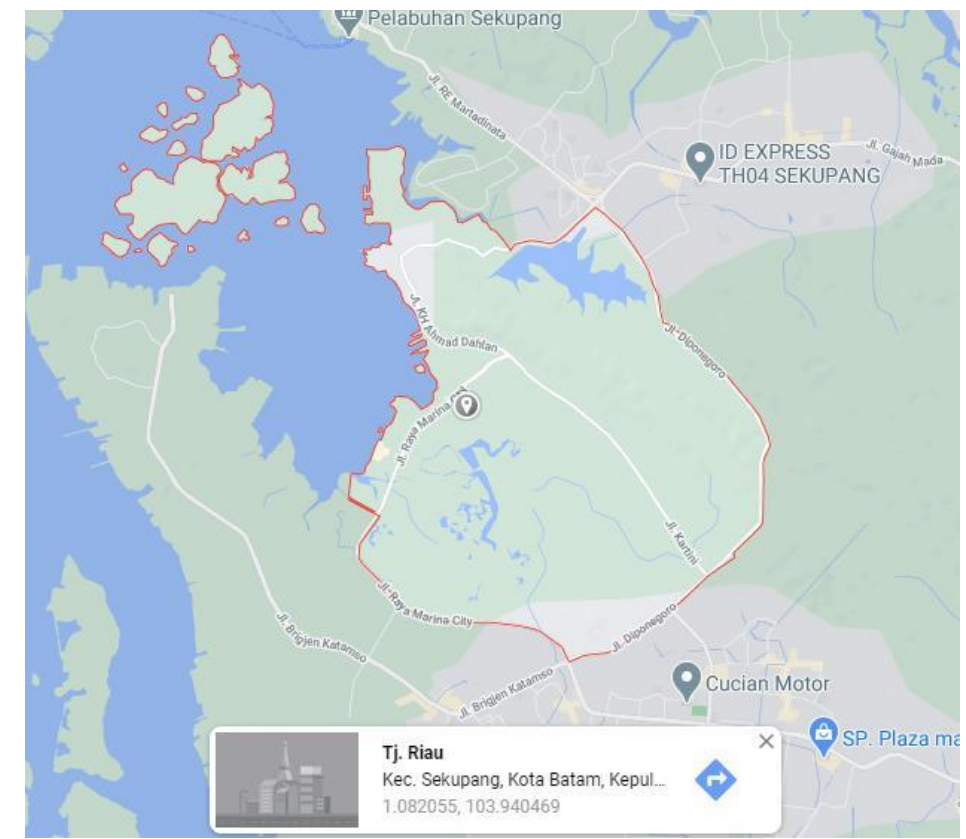

Gambar 1. Kawasan wilayah Kampung Tua, Tanjung Riau

\section{Kajian Pustaka}

Di dalam Lingkungan permukiman Rumah Melayu Tradisonal, disamping kampung, terdapat koto yang juga merupakan tempat terbentuknya kesatuan kehidupan sosial budaya Melayu. Koto dapat didefinisikan sebagai cikal sebuah kampung Melayu dan sekaligus sebagai kampung tertua yang masih dipelihara dan dijaga oleh komunitas (suku). Kesukuan ini- lah yang tradisi Melayu antar generasi. Setiap suku yang dipimpin oleh Penghulu yang terbantu sebagai orang yang memegang kekuasaan informal yang mengatur kehidupan sosial budaya keseharian. Penghulu ini dipercaya sebagai komponen axial yang menjaga implementasi nilai sacral budaya atau nilai tradisional (Milner, 2009). Tidak hanya menegakkan kekuasaan informal, Koto juga tempat yang memiliki rumahrumah Melayu tradisional yang masih dijaga dan dipelihara. Setiap rumah di Koto merupakan representasi dari sebuah suku; pecahan kebudayaan. Rumah- rumah ini juga 
menjadi fundamen penting bagi suku, mau pun bagi keturunan dari suku tersebut. Lebih jauh untuk saat ini, karakter dan elemen rumah tua ini menjadi acuan dalam mengembangkan arsitektur lokal yang sudah semakin memperkaya kosa kata arsitektur Melayu secara umum

\section{Metode Penelitian}

Penelitian ini menggunakan metode pendekatan kuantitatif dan kualitatif yang bersifat desrkriptif, yaitu memberikan gambaran atau fenomena dari yang diteliti dengan menganalisa lokasi tersebut. Pengumpulan data dilakukan dengan observasi lokasi, wawancara, dan dokumentasi. Pemilihan lokasi tersebut dikarenakan lokasi yang strategis yang berada dipusat kota sebagai tempat berkunjungnya wisatawan dan lokasi tersebut menyediakan berbagai fasilitas yang memadai jika dikembangkan.

\section{Hasil dan Pembahasan}

\subsection{Penggunaan Ruang Luar Terhadap Orientasi Bangunan Rumah Melayu di Daerah Pesisir Kampung Tua Tanjung Riau}

Rumah Melayu dapat diidentifikasi apabila memiliki tiga ciri fisik di dalam konstruksinya, yaitu : fakta bahwa rumah tersebut berbentuk panggung, bentuk atap pelana, dan finishing atap dengan gable-finials. (Firzal, 2015). Selain ciri tersebut, rumah melayu juga memiliki ornamen dan ragam hias yang kaya, bentukan ukiran yang sangat indah, motif-motif yang tidak hanya sebatas ukiran, namun memiliki filosofi dan makna yang dalam (Faisal, 2019).

Kampung Tua Tanjung Riau tergolong sebuah Kampung Melayu dikarenakan masih adanya nilai arsitektur melayu yaitu bentukan strukturnya yang dibangun berbentuk panggung. Rumah-rumah di Kampung Tua Melayu umumnya merupakan rumah panggung yang dibangun tepat diatas permukaan air. Berbeda dengan rumah-rumah melayu pada umumnya yang terdapat di pinggiran sungai atau di daratan, rumah melayu di Kampung Tua Tanjung Riau umumnya tidak lagi memiliki ruang luar atau halaman pada orientasi bangunan. Hal itu dikarenakan rumah yang dibangun tepat diatas air mengakibatkan ruang luar bangunan hanya digunakan sebagai jalan menuju jalan utama, juga karena pola permukiman di Kampung Tua Tanjung Riau yang sangat padat membuat minim adanya ruang luar.

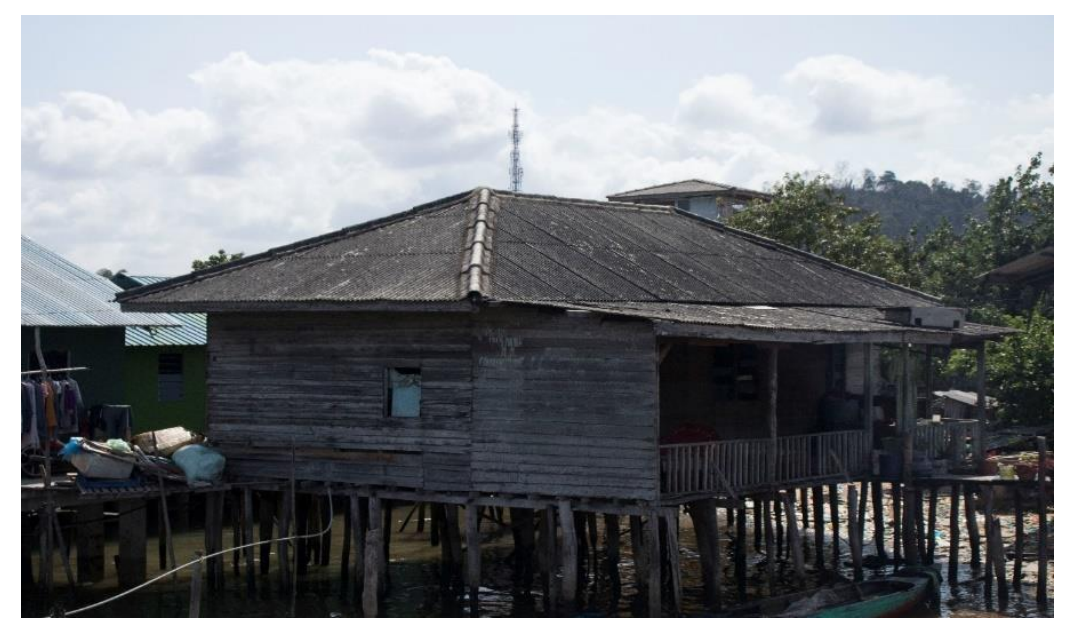

Gambar 2. Rumah Melayu Pesisir Kampung Tua, Tanjung Riau 
Rumah diatas merupakan salah satu rumah hasil survey yang telah kami lakukan di Kampung Tua Tanjung Riau. Rumah ini dibangun dengan konstruksi panggung, tepat diatas permukaan air, dan berorientai ke laut. Rumah melayu yang umumnya memiliki ruang luar yang luas dan dapat digunakan untuk beraktivitas bercocok tanam (sesuai dengan kebiasaan masyarakat melayu), tidak lagi ada di rumah-rumah yang berlokasi di Kampung Tua Tanjung Riau. Seperti yang dapat dilihat, ruang luar bangunan hanya berukuran kecil dan digunakan sebagai jalan setapak menuju ke daratan (jalan utama).

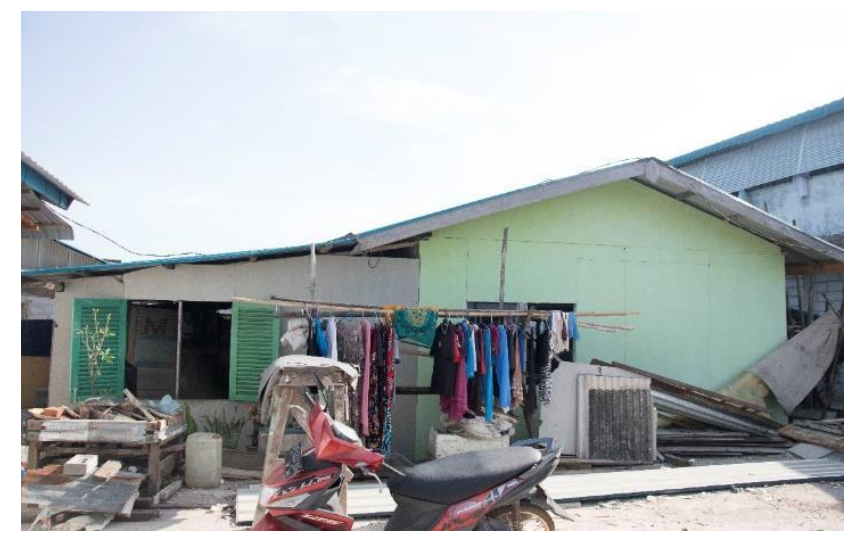

Gambar 3. Rumah Melayu Kampung Tua, Tanjung Riau

Rumah tradisional Melayu memiliki banyak jendela dan dinding padat dengan memberikan ventilasi yang baik, dan ornament yang menarik (Faisal, 2019). Pernyataan terkait rumah tradisional melayu yang diungkapkan oleh Faisal (2019) sudah sangat sulit ditemukan di Kampung Tua Tanjung Riau. Rumah diatas merupakan salah satu rumah melayu berorientasi ke arah laut yang memiliki ruang luar yang lumayan luas dibandingkan rumah lainnya yang berorientasi ke arah laut. Namun, ruang luar sudah tidak dipergunakan lagi seperti ruang luar pada rumah melayu pada umumnya, rumah ini menggunakan ruang luar nya untuk menjemur pakaian dan meletakkan barang-barang lainnya. Padatnya permukiman, kurangnya bukaan, dan penggunaan ruang luar yang tidak maksimal membuat keadaan di kawasan terasa pengap.

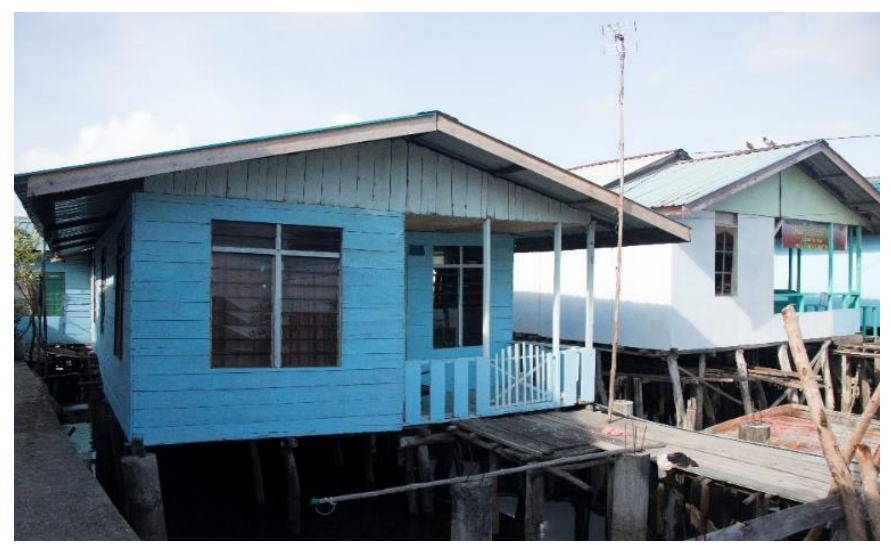

Gambar 4. Rumah Melayu Pesisir Kampung Tua, Tanjung Riau

Rumah melayu memiliki ornamen dan ragam hias yang kaya, bentukan ukiran dan yang sangat indah, motif-motif yang tidak hanya sebatas ukiran, namun memiliki filosofi dan makna yang dalam. Ciri unik lainnya dari rumah tradisional adalah ornamen ukiran kayu, 
yang kebanyakan terinspirasi oleh interpretasi flora dan fauna lokal (Firzal, 2015). Di daerah yang telah kelompok kami survey sebelumnya, rumah melayu yang teridentifikasi memiliki nilai melayu yang sudah sangat berkurang, seperti pada rumah melayu dibawah ini.

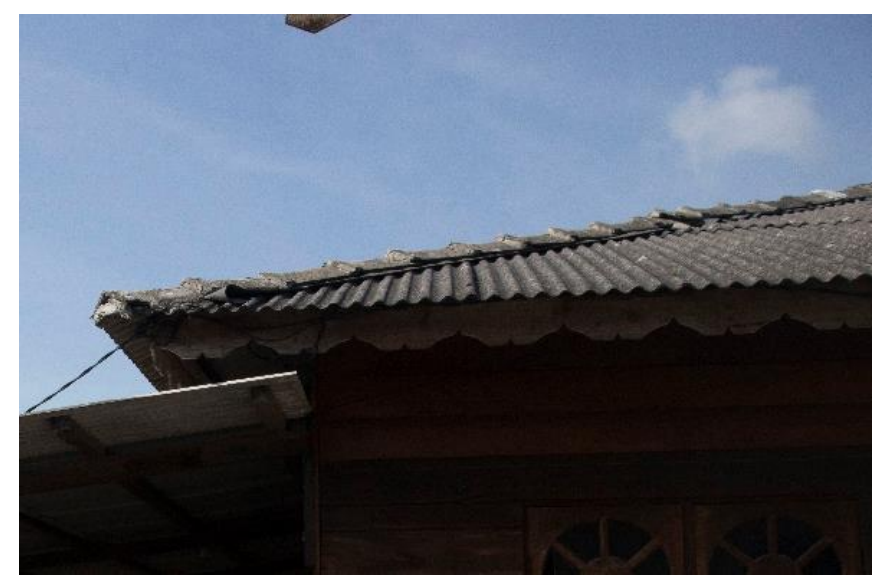

Gambar 5. Atap Rumah Melayu Pesisir Kampung Tua, Tanjung Riau

Rumah ini merupakan rumah yang teridentifikasi sebagai rumah melayu yang masih memiliki karakteristik lebih banyak dibandingkan rumah-rumah lainnya. Umumnya rumah melayu dilengkapi dengan berbagai ornament, namun sudah jarang ditemukan ornament pada rumah-rumah melayu di Kampung Tua Tanjung Riau. Rumah ini merupakan satusatunya rumah melayu yang masih memiliki nilai karakteristik ornament berupa hiasan dibawah atap, yang dapat kami temukan di daerah lokasi yang telah kami survey sebelumnya ornament berupa hiasan dibawah atap, yang dapat kami temukan di daerah lokasi yang telah kami survey sebelumnya.

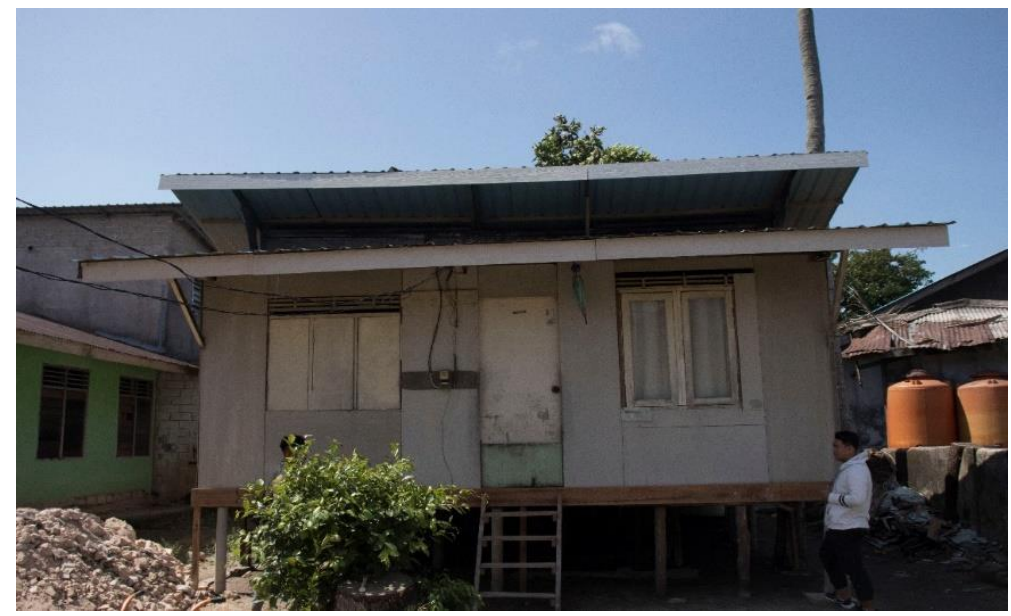

Gambar 6. Rumah Melayu Pesisir Kampung Tua, Tanjung Riau

Rumah panggung tidak hanya diciptakan sebagai respons terhadap lingkungan, akan tetapi juga merupakan bentuk tanggapan terhadap kebutuhan untuk memenuhi sosioekonomi dan persyaratan budaya masyarakat (Yuan dalam Firzal, 2019). Rumah berarsitektur melayu diatas ini merupakan perwujudan dari pernyataan tersebut. Rumah ini menggunakan ruang dibawah panggung rumah untuk memenuhi kebutuhan sosioekonomi penghuni. Penghuni merawat beberapa ayam, dan ruang dibawah rumah menjadi 
tempat bernaung ayam tersebut.

\subsection{Demografi Penduduk}

Berdasarkan laporan jumlah penduduk tahun 2010, jumlah penduduk di Kelurahan Tanjung Riau tercatat berjumlah 12.502 Jiwa dengan jumlah Kepala Keluarga (KK) sebanyak 4.130 KK. Untuk mengetahui kondisi kependudukan di Kelurahan Tanjung Riau, berikut ini adalah komposisi penduduk berdasarkan jenis kelamin yang diikuti komposisi penduduk yang lainnya.

\begin{tabular}{|c|l|r|}
\hline No & \multicolumn{1}{|c|}{ Mata Pencaharian } & \multicolumn{1}{c|}{ Jumlah } \\
\hline 1 & Petani / Buruh Tani & 216 \\
\hline 2 & Nelayan & 161 \\
\hline 3 & Buruh Migran & 2578 \\
\hline 4 & PNS/ TNI/ POLRI & 52 \\
\hline 5 & Pengusaha kecil dan menengah & 56 \\
\hline 6 & Karyawan Swasta & 79 \\
\hline jumlah & $\mathbf{3 1 4 2}$
\end{tabular}

Tabel 1. Demografi Penduduk wilayah Kampung Tua, Tanjung Riau

Mata pencarian penduduk di Kelurahan Tanjung sangat beragam seperti petani, nelayan, pegawai negeri, pengusaha dan karyawan swasta. Komposisi Penduduk Berdasarkan Mata Pencaharian tesebut dapat dilihat dari jumlah mata pencarian penduduk yang paling dominan di Kelurahan Tanjung Riau adalah penduduk dengan mata pencarian buruh migran dengan persentase $82 \%$, sedangkan yang terkecil adalah penduduk dengan mata pencaharian sebagai pegawai negeri, pengusaha, dan TNI dengan persentase $2 \%$.
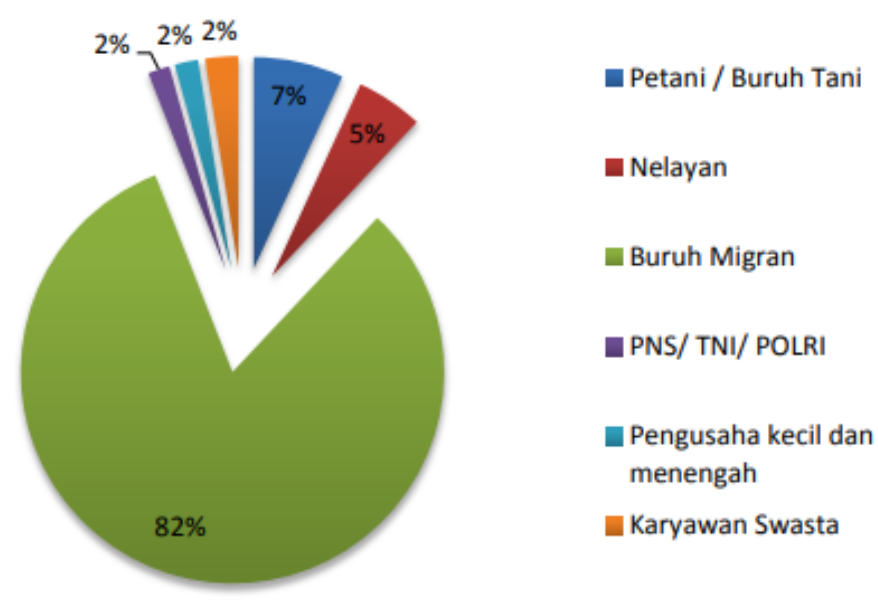

Diagram 1. Demografi mata pencarian penduduk wilayah Kampung Tua, Tanjung Riau

\section{Kesimpulan}

Dari analisa tersebut kami menemukan beberapa masalah yang timbul yaitu :

1. Beberapa rumah tinggal masyarakat sana yang telah kami lihat membuktikan bahwa nilai karakteristik arsitektur Melayu sudah mulai ditinggalkan di daerah 
permukiman Kampung Tua Tanjung Riau. Kampung Tua yang mendapat sebutan Kampung Melayu mulai mengalami penurunan pada nilai arsitektur melayunya, terbukti dengan rumah-rumah hasil survey yang telah dikategorikan sebagai rumah Melayu, hanya memiliki beberapa nilai karakteristik yang mencirikan sebagai rumah Melayu. Tidak seperti rumah Melayu seutuhnya yang memiliki hampir seluruhnya karakteristik rumah melayu, kini di permukiman Kampung Tua Tanjung Riau, rumah yang berhasil dikategorikan sebagai rumah Melayu, hanya memiliki 1 atau 2 karakteristik yang mencirikan rumah melayu tersebut. Tata letak bangunan dan jalur akses juga masih belum tertata rapi. Sebagian ada yang besar dan ada yang kecil. Beberapa rumah tinggal disana juga menyatu satu sama lain.

2. Bahasa Sehari-hari yang mereka gunakan adalah Bahasa Melayu dan Bahasa Indonesia. Selain itu, disana juga menerapkan organisasi kemasyarakatan agar mempererat hubungan antar warga dengan warga masyrakat. Untuk Mata pencaharian penduduk disana lebih dari $80 \%$ yang keluar dari kampong dan menjelajah sebagai buruh migran. Bagi yang tetap tinggal sebagian besar masih melakukan mata pencaharian yang berlokasi / tidak jauh dari sana.

3. Untuk saluran airnya sendiri juga belum tertata rapi. Ada yang membuat saluran air tersebut menuju Perairan langsung dan untuk rumah tinggal panggung yang berada dibawah air, pembuangannya langsung kebawah air. Masyarakat sana juga masih melakukan pembuangan sampah secara sembarangan, sehingga laut disana menjadi tercemar dan kumuh.

Oleh karena itu, agar kampung tua ini dapat beroperasi dengan baik, Menurut kami sistemnya harus ditata ulang semuanya. Pertama dari memperbaiki infrastruktur bangunan rumah tinggal masyarakat dan jalan. Mulai dari penempatan, gaya budaya rumah tinggal yang berada disana, dan pembuatan jalan untuk akses mobil dan pejalan kaki. Saluran pipa untuk air kotor dibuat menuju pembuangan khusus air kotor, melarang masyarakat sana untuk membuang sampah sembarangan dengan menyediakan wadah pembuangan sampah untuk setiap rumah tinggal. Selain itu, Lokasi tersebut juga terkenal dengan kuliner dan budayanya. Hal ini dapat memperluas perkulinerannya agar dapat menjadi destinasi wisata bagi orang luar.

\section{Daftar Pustaka}

Firzal, Yohannes. (2015). Reconstructing SocioCultural Identity: Malay Culture and Architecture in Pekanbaru, Indonesia, Ph.D. dissertation, Newcastle University, Newcastle.

Milner, A. (2009) The Malays. Chichester: John Wiley \& Sons Ltd.

Faisal, G. (2019). Arsitektur Melayu: Identifikasi Rumah Melayu Lontiak Suku Majo Kampar. Langkau Betang: Jurnal Arsitektur, 6(1), 1-12.

Yuan, L.J. (1987) The Malay House : Rediscovering Malaysia's Indigenous Shelter System. Pinang, Pulau Pinang, Malaysia. 